\title{
Evolution of the human-water relationships in the Heihe River basin in the past 2000 years
}

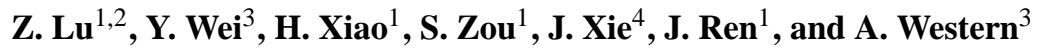 \\ ${ }^{1}$ Key Laboratory of Ecohydrology of Inland River Basin, Cold and Arid Regions Environmental and Engineering Research \\ Institute, Chinese Academy of Science, Lanzhou, China \\ ${ }^{2}$ University of the Chinese Academy of Science, Beijing, China \\ ${ }^{3}$ Australia China Joint Research Centre on River Basin management, Department of Infrastructure Engineering, \\ the University of Melbourne, Parkville, Australia \\ ${ }^{4}$ Key Laboratory of Desert and Desertification, Cold and Arid Regions Environmental and Engineering Research Institute, \\ Chinese Academy of Science, Lanzhou, China
}

Correspondence to: Y. Wei (ywei@unimelb.edu.au)

Received: 30 December 2014 - Published in Hydrol. Earth Syst. Sci. Discuss.: 23 January 2015

Revised: 20 April 2015 - Accepted: 25 April 2015 - Published: 12 May 2015

\begin{abstract}
This paper quantitatively analyzed the evolution of human-water relationships in the Heihe River basin of northern China over the past 2000 years by reconstructing the catchment water balance by partitioning precipitation into evapotranspiration and runoff. The results provided the basis for investigating the impacts of societies on hydrological systems. Based on transition theory and the rates of changes of the population, human water consumption and the area of natural oases, the evolution of human-water relationships can be divided into four stages: predevelopment (206 BC-AD 1368), take-off (AD 1368-1949), acceleration (AD 1949-2000), and the start of a rebalancing between human and ecological needs (post AD 2000). Our analysis of the evolutionary process revealed that there were large differences in the rate and scale of changes and the period over which they occurred. The transition of the human-water relationship had no fixed pattern. This understanding of the dynamics of the human-water relationship will assist policy makers in identifying management practices that require improvement by understanding how today's problems were created in the past, which may lead to more sustainable catchment management in the future.
\end{abstract}

\section{Introduction}

The development of land and water resources within catchments over thousands of years has led to spectacular growth in agricultural production along with increased human consumption of water, significant modification of catchment vegetation, and serious degradation of ecosystems, worldwide (Carpenter et al., 2011; Falkenmark and Lannerstad, 2005; Röckstrom et al., 2009; Vörösmarty et al., 2010). Future human wellbeing may be seriously compromised if we pass a critical threshold that tips catchment ecosystems into irreversible degradation.

Understanding the connections and feedback mechanisms between changes in human activities and hydrological systems in the long term, and uncovering the mechanisms governing the human-water feedback loop, can help us to understand how today's conditions and problems were created in the past, and have important implications for future management (Sivapalan et al., 2012; Liu et al., 2013; Montanari et al., 2013; Savenije et al., 2013). However, at present, there is limited understanding of the major modes of interactions between the human and hydrologic systems over long timescales. Developing such understanding is the aim of social hydrology (Savenije et al., 2013). 
Historical analysis is a key method of socio-hydrology in which hydrological analysis over a long time frame is a key component. Accurate historical data for hydrology, climate, land use, ecology and geomorphology are often unavailable, but hydrological reconstruction that aims to generate longterm data sets could provide a basis for the identification, description and parameterization of feedback mechanisms between human activities and water (Thompson et al., 2013). Empirical reconstructions of changes in single hydrological elements at specific locations have been reported, including precipitation, streamflow, water salt content and lake levels (Turner et al., 2008; Lowry and Morrill, 2011). Whilst these studies are empirically informative, few of them have been conducted on water balance in basins that are facing significant threats such as water over-abstraction, sea level rise, or land use change, or in basins that experience major transitions (Vörösmarty et al., 2010).

In the social science literature, transition is a wellestablished concept. It is "a non-linear process of social change in which the structure of a societal system (energy sector, water management and agriculture) transforms" (Rotmans, 2005). Although there are a considerable number of empirical studies focusing on the dynamics of transition, and in particular on the different stages and processes of transition, they have been criticized for empiricism: good at description but weak at explanation (Wimmer, 2006). There have already been several early attempts at exploring the coevolution of human and water systems. For example, Xiao and Xiao (2004) divided the evolutionary processes of the human-land relationships affected by the water resources in the Ejin region, downstream of the Heihe River basin, into four periods. Geels (2005) studied the trajectories of the co-evolution of water technology and society in presentday Netherlands. Kallis (2010) studied the co-evolution of water resource development in ancient Athens. Pataki et al. (2011) provided an outline of the interplay of sociological and ecological processes in urban water management. Unfortunately, most of them adopted "thick descriptive" approaches that have poor explanatory and predictive ability. Recently, Elshafei et al. (2014) developed a prototype framework for models of social hydrology, including identification of some important feedback loops. The framework aims for more explanatory capability, although the fully parameterized dynamic coupled model has yet to be applied.

The Hexi Corridor, located in western Gansu Province, China, is an important part of the ancient Silk Road established in the Han Dynasty (206 BC-AD 220), and was a trade route between China and western countries that facilitated cultural and economic exchange for approximately 1500 years. It is an arid area supported by oasis ecosystems where water dominates the dynamics of human society and natural systems, and therefore the interactions and feedbacks between humans and water are very prominent. The region has a rich written history of over 2000 years. Over-development of land and water resources over thou- sands of years has significantly modified the catchment vegetation conditions and desertification is a continuing process causing environmental degradation in the region (Xiao and Xiao, 2004, 2008).

The overarching goal of this paper is to reveal the evolutionary processes of human-water relationships in the Heihe River basin, an important part of the Hexi Corridor, for a period spanning approximately 2000 years over which hydrologic, social and environmental systems interacted. The specific objectives are to reconstruct the water balance on the basin scale over the past 2000 years and to determine the development stages of the evolution of the human-water relationships. The analysis is used to gain important understanding of the human-water relationships and to provide guidance for the region's sustainable development.

\section{Methods}

\subsection{Study area}

We selected the Heihe River basin (HRB) in northwestern inland China as our case study area. The HRB is located in the central Hexi Corridor, one of the most arid regions in the world. It covers approximately $130000 \mathrm{~km}^{2}$ and is located at the climatic intersection between the Westerlies and the East Asian summer monsoon (Fig. 1). Many civilizations and cultures have flourished there, including the Siba culture, the Juyan Wooden Slips and the literature of Heishui (Cheng et al., 2011; Shi, 2007). The rise and fall of civilizations in the HRB is closely linked with water: when there is water, there are oases and flourishing societies; when there is no water, there are deserts and diminished human activities.

The Qilian Mountains are the principal water source areas of the Heihe River. They have an elevation varying between 2000 and $5500 \mathrm{~m}$ and a mean annual precipitation varying between 250 and $500 \mathrm{~mm}$. The midstream oases are a part of the Hexi Corridor, with elevations between 1000 and $2000 \mathrm{~m}$ and mean annual precipitation ranging from 100 to $250 \mathrm{~mm}$. The lower reaches are located on the arid Alaxa Plateau where the mean annual precipitation is less than $50 \mathrm{~mm}$ (Qin et al., 2010). The Heihe River is the second longest inland river in China, with a length of $821 \mathrm{~km}$. Starting from the upstream Yingluoxia Hydrological Station (YLX), the Heihe River flows northward into its midstream area. Flows out of the midstream area are measured at the Zhengyixia Hydrological Station (ZYX), and it finally flows into terminal lakes in the downstream areas. Flow from the upper catchment provides water supplies for agricultural production and ecosystem stabilization in the middle and lower reaches of the HRB.

The HRB is an important area for grain production in China and is a highly developed irrigation district with an unremittingly agricultural history dating back nearly 2000 years. Intensive and unsustainable utilization of water resources in the middle reaches of the basin has led to 

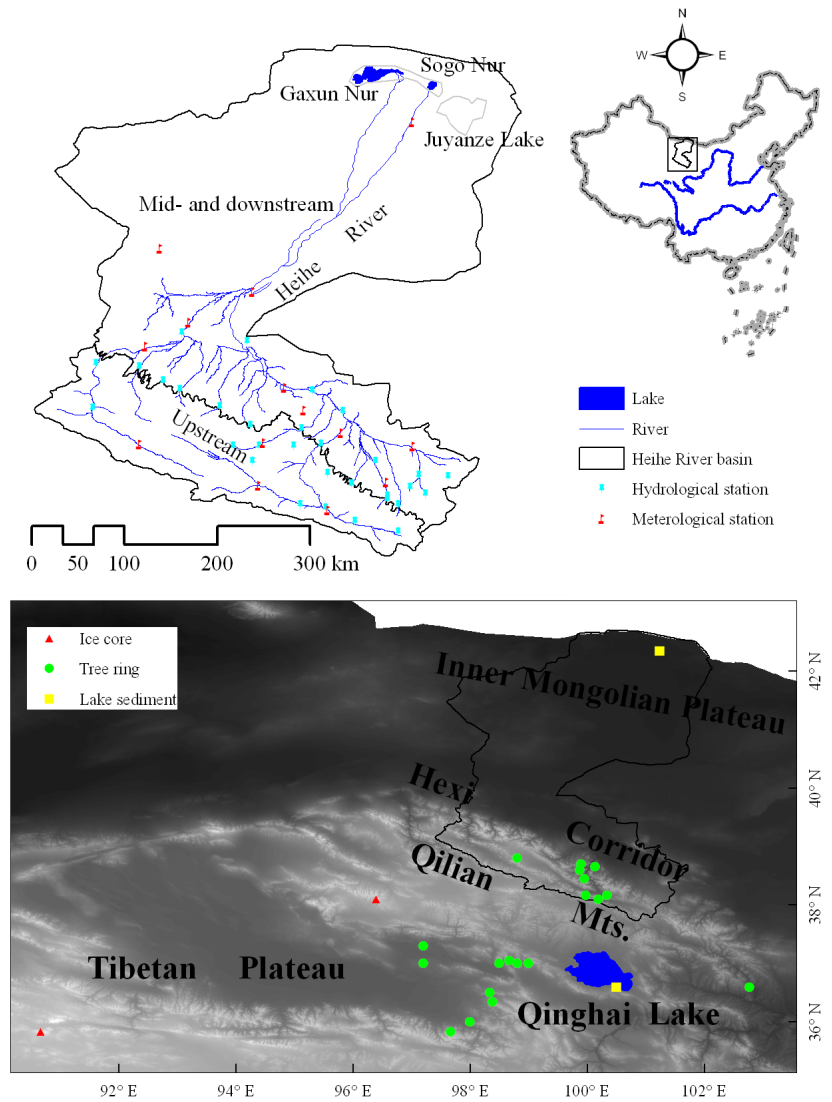

Figure 1. Location of the Heihe River basin and locations of ice core, tree ring and lake sediment data.

a sharp decrease in water supply to the lower reaches during the last 50 years (Zhou and Yang, 2006). As a consequence, the ecosystems in the lower reaches have been degraded by land desertification, more frequent sandstorms, and the drying of terminal lakes. Therefore, the HRB is a compelling case study area for an analysis of the co-evolution of humanwater systems on a basin scale.

\subsection{Study period}

We selected the past 2000 years as our study period. This timescale represents a period in which dramatic changes in climate, land use, runoff, management policy, population, societal development and catchment ecological conditions have occurred. These are major variables affecting the water cycles of river basins. It is also a time of significant civilization development in China, for which there is a wealth of documentary evidence available (Holmes et al., 2009; Zheng and Wang, 2005).

We reconstructed the co-evolutionary processes of societal development and hydrological systems based on seven periods in the past 2000 years using the results of Shi (2010), Wang et al. (2013) and Xie et al. (2013) (Table 1). This reconstruction was dependent on adequate land use informa- tion, which resulted in some limitations in developing a contiguous hydrological data set over this long time frame.

\subsection{Reconstructing the evolutionary processes of catchment water balance}

We used annual water balance partitioning to provide insights into the evolutionary processes of human-water relationships on a basin scale. Such partitioning is widely used as a signature of hydrologic regimes when catchments experience changes in precipitation regimes, temperature and land use change (Budyko, 1974; Sivapalan et al., 2003). For this study, the water balance equation can be written as

$P+R_{\text {in }}=E+R_{\text {out }}$,

where $P$ and $E$ are precipitation and evapotranspiration in the midstream and downstream areas of the HRB, respectively; $R_{\text {in }}$ is the streamflow from the upstream part of the HRB into the midstream area; and $R_{\text {out }}$ is the volume of water flowing into the terminal lakes of the downstream areas. In arid regions, soil water content is very low, and the groundwater levels were stable over historical periods, so changes in soil water content and groundwater are negligible and not included in Eq. (1).

Due to a lack of measured data in historical periods, the reconstruction of $P, R_{\mathrm{in}}$ and $E$, and validation of the derived $R_{\text {out }}$ from Eq. (1), are important steps for developing catchment water balance over the long-term time frame necessary for understanding the co-evolutionary process of human-water relationships.

\subsubsection{Reconstruction of precipitation $(P)$ in the midstream and downstream areas}

We estimated precipitation $(P)$ in historical periods based on instrumental data in the most recent period and changes in paleoclimatic conditions. Ren et al. (2010) reconstructed the mean precipitation sequence of the whole HRB for the past 2000 years using historical drought and flood sequences, based on the good correlation between drought and flood disasters and precipitation in the 40 years from 1956 to 1995 $\left(R^{2}=-0.892\right)$. We reconstructed the distributed precipitation $(P)$ in the midstream and downstream areas in historical periods as follows. The mean precipitation from the instrumental record for 1956 to 1995 , when there were continuous records at ten meteorological stations, was multiplied by the ratio of the precipitation in each historical period reconstructed by Ren et al. (2010) to the precipitation in the measured period. The instrumental precipitation data in the recent period were obtained from the China Meteorological Administration. 
Table 1. Seven periods selected in the past 2000 years.

\begin{tabular}{lllll}
\hline Dynasty & Start & End & Main production & Selected periods \\
\hline Han Dynasty & 206 BC & AD 220 & Agriculture & The beginning of the 1st century AD \\
Wei-Jin era & AD 220 & AD 420 & Animal husbandry & The end of the third century AD \\
Tang Dynasty & AD 618 & AD 907 & Agriculture & The mid-8th century AD \\
Yuan Dynasty & AD 1271 & AD 1368 & Animal husbandry & The end of the 13th century AD \\
Ming Dynasty & AD 1368 & AD 1644 & Agriculture & The mid-16th century AD \\
Qing Dynasty & AD 1644 & AD 1912 & Agriculture & The mid-18th century AD \\
The Republic of China era & AD 1912 & AD 1949 & Agriculture & The 1940s \\
\hline
\end{tabular}

\subsubsection{Reconstruction of streamflow into the midstream area: $\boldsymbol{R}_{\mathrm{in}}$}

Dendrochronologically based hydrological reconstructions have been widely used to extend existing instrumental streamflow records, as streamflow variations correlate well with tree ring-width series (Woodhouse et al., 2006; Saito et al., 2008). There are many streamflow reconstruction studies based on tree ring analyses for the Qilian Mountains. The longest streamflow record in this region is about 1400 years, developed by Yang et al. (2012), then 1300 years by Kang et al. (2002) and 1000 years by Qin et al. (2010). None of these streamflow reconstructions completely spans the 2000 years of interest.

In order to reconstruct the historical streamflow in the upstream area of the HRB $\left(R_{\text {in }}\right)$ over the past 2000 years, we firstly analyzed the consistency of the historical streamflow reconstructions of Yang et al. (2012), Kang et al. (2002) and Qin et al. (2010), and selected the two most reasonable reconstructions based on the humidity changes in this region as reflected by other proxy indices, e.g., lake sediments and ice cores. The shorter one was used to extend the historical series and the longer one was used to validate the extension where these two reconstructions did not overlap. We then extended the selected reconstructed streamflow up to 2000 years by using the reconstructed precipitation and a relationship established between the selected streamflow reconstruction and the existing precipitation reconstruction in the upstream area. All the streamflow reconstructions focused on the mountainous region of the main stream of the Heihe River (Fig. 1). Therefore, in order to obtain the streamflow flowing into the midstream area $\left(R_{\text {in }}\right)$, we multiplied the streamflow at YLX by the ratio of the total streamflow from the upstream area of the HRB to the streamflow at YLX, based on the instrumental data in the recent 50 year period. The instrumental streamflow in the recent period was obtained from the Hydrographic Service of Gansu Province.

\subsubsection{Estimating $E$ based on reconstructed land use}

$E$ in Eq. (1) was calculated using the top-down method of the Budyko hypothesis. We used the equations developed by $\mathrm{Fu}$ (1981) (for details, see Fu, 1981, and Zhang et al., 2004), which are

$$
\begin{gathered}
\frac{E}{P}=1+\frac{E_{0}}{P}-\left[1+\left(\frac{E_{0}}{P}\right)^{w}\right]^{1 / w}, \\
\frac{E}{E_{0}}=1+\frac{P}{E_{0}}-\left[1+\left(\frac{P}{E_{0}}\right)^{w}\right]^{1 / w},
\end{gathered}
$$

where $E_{0}$ is potential evapotranspiration. $E_{0}$ was estimated on a daily timescale using the Penman-Monteith equation for 1966 to 1995 . The Penman-Monteith equation has been acknowledged as the best method for this region (Zhao and $\mathrm{Ji}$, 2010). It is known that many factors influence $E_{0}$, and it is difficult to clearly determine the changes in $E_{0}$ in historical periods without instrumented data. However, it is recognized that air temperature is one of most important factors influencing $E_{0}$. As the range of the temperature change over the study period was not more than $2^{\circ}$ in this region (Zheng et al., 2010), and as Zhang et al. (2014) found that the $E_{0}$ increased by only $1.16 \mathrm{~mm}$ per month for a temperature increase of $2^{\circ}$ in the Gulang River basin (next to the Heihe River basin), it was assumed that $E_{0}$ in the HRB was constant over the study period and the same as instrumented times. The term $w$ is a catchment-scale model parameter determining the evaporation ratio $(E / P)$ for a given $E_{0} / P$. Theoretically, $w$ should vary between land use types and could change with time, depending on the type and intensity of crops. Unfortunately, due to the lack of historical documents or data for the natural oases (forest and grassland) in this region, it is impossible to characterize $w$ for the natural oases in historical periods. In addition, in Eqs. (2) and (3), when $w$ is larger than 3, the impact of changes in $w$ on $E$ is small, especially in arid regions, where $E_{0} / P$ is large. In such situations, the available water for evapotranspiration becomes the determining factor (Zhang et al., 2001, 2004). Therefore, the value of $w$ for HRB was set to 3.5 following Yang et al. (2007). The sources of water supply for $E$ include precipitation, groundwater, and irrigation water, so $P$ in Eqs. (2) and (3) can be replaced as follows.

For cultivated oases : $P_{\text {crop }, i}=P_{i}+J$.

For natural oases : $P_{\mathrm{veg}, i}=P_{i}+G_{\mathrm{veg}}$,

where $P_{\mathrm{crop}, i}$ and $P_{\mathrm{veg}, i}$ are the precipitation equivalent in period $i$ for crop and natural oases, respectively; $P_{i}$ is the actual 
precipitation in period $i ; J$ is irrigation; and $G_{\text {veg }}$ is the water consumed from groundwater by the natural oases. In this arid region, there is no agriculture without irrigation. According to Xiao and Xiao (2008), flood irrigation has been the main irrigation method in northern China since the Han Dynasty. The main crop varieties, water conservancy facilities, irrigation methods and farming conditions have remained almost unchanged from the Han Dynasty to the early modern period according to Wang's (2003) research on the development history of farm irrigation in the Heihe River basin, which, to our understanding, is the most comprehensive study on historical agricultural irrigation in this region. Wheat was the major crop and single wheat was the main cropping pattern in this region; therefore, the annual irrigation volume was set at $500 \mathrm{~mm}$ for the historical periods. Since the 1980s, annual irrigation applications in this region have increased from 500 to $650 \mathrm{~mm}$ as the cropping pattern has evolved from single wheat to double cropping with wheat and maize (Wang et al., 2005; Shi et al., 2011).

Irrigation water was obtained by surface water withdrawal from upstream reaches in historical periods; however, it has been both pumped from groundwater and diverted from surface water since 1949, as the surface water resource was insufficient for rapid development of agriculture. The development of pumping and drilling technology during this period also facilitated this change. $G_{\text {veg }}$ was set at $225 \mathrm{~mm}$ per year for natural oases based on Wang et al. (2005). For unused land, where the groundwater level was deep, the only water supply was precipitation.

The total ET of the basin is given by

$E_{\text {total }}=\sum_{l=1}^{3} E_{l} \times S_{l}$,

where $E_{\text {total }}$ is the total evapotranspiration of the basin; and $l$ is the number of the land use types: cultivated oases, natural oases, and unused land. $E_{l}$ is the evapotranspiration from land use type $l$, and $S_{l}$ is the area of land use type $l$.

The maps of cultivated oases in historical periods were downloaded from the Heihe Plan Science Data Center: www. heihedata.org/heihe (Xie, 2013). As the historical reconstructions of the natural oases in this region were not available in the literature, we reconstructed them based on the following two assumptions about the reclamation of cultivated oases based on previous results (Li, 1998; Wu, 2000; Xie et al., 2009): (1) people selected the regions with natural oases (grassland and forest) rather than desert for reclamation in the historical periods because the former have better water and soil conditions in these arid regions, and (2) once the reclaimed farmlands were abandoned and without vegetation cover, they were subsequently desertified because of winddriven sand and burial by dunes. The hundreds of ruins of towns along the Silk Road in the vast deserts of northwestern China are clear evidence of this change in oasis systems. Then, it is known that the expansion of the farmland from the desert in this region started after 1975; we considered the total area of oases from the first period to the period of 1975 as the largest area of oases in historical periods, which included cultivated and natural oases. In each period, the area of cultivated oases had reconstructed data (Xie, 2013); then, the area of natural oases was obtained by deducting the area of cultivated oases in the particular period and the area of cultivated oases abandoned in the past periods from the total oasis area, and the remainder was considered unused land.

Based on the land use reconstructions, precipitation reconstructions and estimated $E_{0}$, the $E$ in Eq. (1) was obtained using Eqs. (2) and (3). The data sources used for calculation of $E$ and reconstruction of land use included land use data obtained for three periods by remote sensing (1975 Landsat MSS, 2000 and 2010 satellite TM and ETM+ data), the historical atlas of China (Tan, 1996), and meteorological data from the China Meteorological Administration, including daily mean, maximum and minimum air temperatures, wind speed, and relative humidity.

\subsubsection{Validating $\boldsymbol{R}_{\text {out }}$ with reconstructed evolution of the terminal lakes}

The input volumes of water to terminal lakes $R_{\text {out }}$ were derived from the reconstructed precipitation, $E$ based on the reconstructed land use, and reconstructed streamflow $R_{\text {in }}$ using Eq. (1). We validated the derived $R_{\text {out }}$ with the lake evolution reconstructed by previous research on the lithology, geochemistry and mineralogy of lacustrine sediment depth profile sequences.

As sediment profiles of lakes in arid zones sensitively reflect changes in climate and human activities, they are regarded as excellent resources for palaeoclimate research (Jin et al., 2004). Lacustrine sediment sequences have been widely used for deducing the mass balance between the inflow water volume and evaporation from terminal lakes, climate change and human activity (Jin et al., 2004, 2005). For example, grain size distributions of lacustrine sediments directly reflect water dynamics, and soluble salt content reflects the chemical characteristics of lake water, which is affected by climate and inflow water (Jin et al., 2004).

Due to the unavailability of systematic and consistent studies on lake evolution in the HRB, we validated the derived $R_{\text {out }}$ values based on the changes in input volumes of water to the terminal lakes in downstream areas, as they reflect changes in the hydrologic cycle involving precipitation, land use, evaporation and runoff in the upper and middle reaches. $R_{\text {out }}$ directly influences the processes of expansion and shrinkage of surface area, sediment deposition and salinization of the terminal lakes. When the input volume of water to the terminal lakes is relatively abundant, lake area extends, lake water level rises, lake water has smaller salt concentrations, and the sediment deposition environment is relatively stable, and vice versa. 

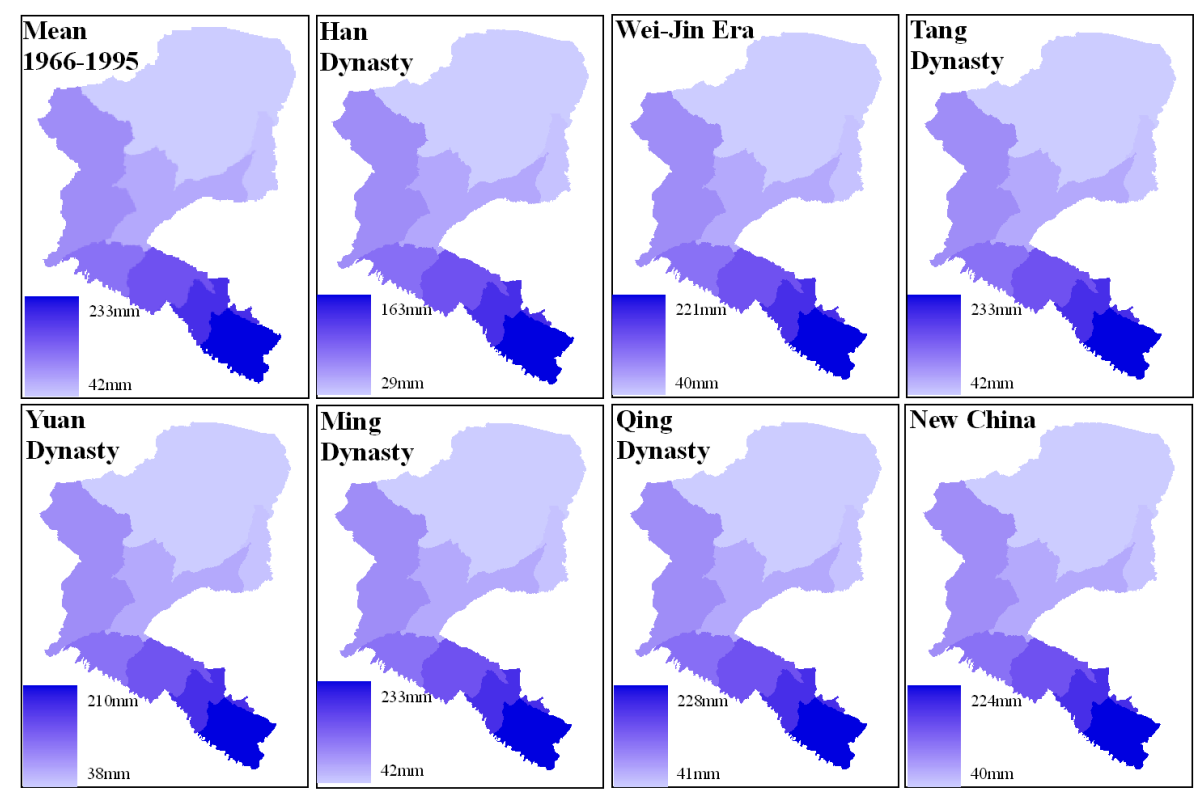

Figure 2. The reconstructed precipitation in historical periods in midstream and downstream areas of the HRB.

The data and information sources used for reconstruction of the evolution of the terminal lakes include all studies on the palaeoenviromental evolution in the downstream area of the HRB from lakes Sogo Nur, Gaxun Nur and Juyanze. The evolution of the terminal lakes in the Heihe River experienced three periods: Juyanze from the Warring States period to the Yuan Dynasty, Juyanze-Gaxun Nur from the Yuan Dynasty to the Ming Dynasty, and Gaxun Nur-Sogo Nur from the Ming Dynasty to AD 1961 (Chen, 1996). The data include granularity, soluble salt, sedimentary pigment, organic carbon content, and groundwater level (Jin et al., 2004, 2005; Qu et al., 2000; Zhang et al., 1998).

\subsection{Determining the development stages of evolutionary processes of human-water relationships}

River basins are co-evolving social-ecological systems in which water management decisions affect environmental outcomes that are subject to societal conditions. We interpreted and determined the key states of the evolutionary processes of the human-water relationships in the HRB based on the transition theory of social science. Transition theory is one of the most relevant approaches to understand the evolution of societal systems and support the management of sustainable development (Tàbara and Ilhan, 2008). In general terms, a transition can be understood as the process of change of a system from one stage of a dynamic state to another. According to Rotmans (2005), a set of typological phases can be identified in a transition: (1) predevelopment, (2) take-off, (3) acceleration, and (4) stabilization. In the predevelopment stage, a change occurs marginally or imperceptibly, while af- ter take-off, a rapid process of societal change occurs until another state is reached, in which the speed of change decreases again (Tàbara and Ilhan, 2008). Transitions can fail at any stage.

A transition can be measured and assessed by indicators that could be variables with actual physical meanings, or their surrogates. In this study, we used human water consumption and natural oasis area as indicators to understand the evolutionary processes of the human-water relationships in the HRB over the past 2000 years. Human water consumption, the difference between evapotranspiration and precipitation in cultivated land areas, reflects the consequence of human societal development for water cycles. The area of natural oases reflects water supporting the environment. We used the direction and rate of change $(k)$ of these two indicators over time to divide the human-water relationship into different development stages. Both the natural oasis area and human water consumption were obtained using the methods above.

\section{Results}

\subsection{Reconstructed precipitation $(P)$ in midstream and downstream reaches}

The ratios of precipitation for seven selected historical periods to the current period, for the whole HRB, were 0.7, $0.95,1,0.9,1,0.98$ and 0.96 , respectively. The precipitation in midstream and downstream areas for each historical period was then obtained by multiplying the mean instrumentmeasured precipitation from data for 1966 to 1995 at ten meteorological stations by these proportions (Fig. 2). The pre- 


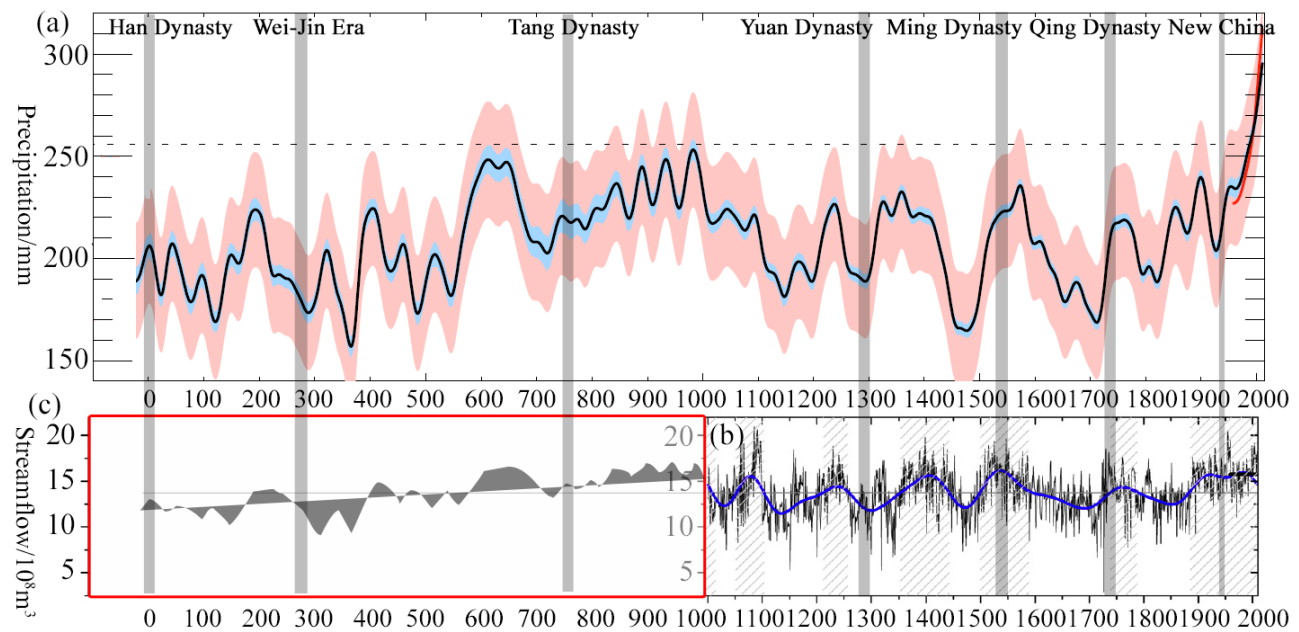

Figure 3. (a) Yang et al.'s (2014) annual precipitation reconstruction for the Qilian Mountains over the last 2000 years, with 50 year smoothing. (b) Qin et al.'s (2010) annual streamflow reconstruction spanning the last millennium with 50 year smoothing at YLX. (c) Our extension of the streamflow from 0 to AD 1000 based on the Yang et al. (2014) precipitation reconstruction and the Qin et al. (2010) streamflow reconstruction.

cipitation in historical periods decreased from the midstream to downstream reaches, was least in the Han Dynasty, and was similar to the present level in the Tang and Ming dynasties.

\subsection{Reconstructed streamflow flowing into midstream reaches $\left(\boldsymbol{R}_{\text {in }}\right)$}

The streamflow reconstruction of Qin et al. (2010) was used to extend the measured streamflow reconstruction, and the streamflow reconstruction of Yang et al. (2012) was used to validate it. It was found that the streamflow record reconstructions obtained by Yang et al. (2012), Qin et al. (2010), and Kang et al. (2002) for the period AD 1000-2000 are generally consistent; however, discrepancies occurred around the years 1290, 1530, 1690, 1840 and 1910. The streamflow reconstructions by Yang et al. (2012) and Qin et al. (2010) were more consistent with the changes in regional humidity suggested by paleoclimate results for this region. The paleoclimatic series were derived from tree rings from living trees or archaeological woods in the Qilian Mountains and the Tibetan Plateau (Yang et al., 2014; Sheppard et al., 2004; Shao et al., 2010), sediments in Qinghai Lake (Shen et al., 2001), and ice cores in Dunde (Liu et al., 1998). Therefore, these two reconstructions were considered to be the more reasonable ones.

It is known that the annual streamflow at YLX and mean precipitation in the Qilian Mountains region changed consistently over the past 50 years (Xiao and Xiao, 2008). It was found that precipitation reconstructions of Yang et al. (2014) (Fig. 3a) and streamflow reconstructions of Qin et al. (2010) (Fig. 3b) changed consistently in the last 1000 years. We derived a linear relationship between them as follows: $R_{\text {Qin et al. (2010) }}=0.2771 \times P_{\text {Yang et al. (2014) }}+80.632$. We used this relationship to extend the streamflow reconstruction back to the period 0 to AD 1000 at YLX (Fig. 3c). The extended streamflow reconstruction is consistent with the streamflow reconstruction of Yang et al. (2012) for the period from AD 575 to 1000 . Over the whole study period, the reconstructed streamflows into midstream areas $\left(R_{\text {in }}\right)$ varied between about 2.6 and 4.0 billion $\mathrm{m}^{3}$ per year. Streamflow peaked in recent years due to abundant precipitation together with glacier melt and snowmelt in the upstream areas due to rises in temperature.

\subsection{Reconstructed historical land use and land cover}

The reconstructions of land use for the seven historical periods and three land use maps for 1975, 2000 and 2010 obtained by image interpretation are shown in Fig. 4. The areas of cultivated oases changed significantly over historical periods. It was large in the Han Dynasty, and then gradually decreased in area until the Yuan Dynasty. From the Ming Dynasty, it increased gradually, and finally reached a peak in the period of modern China. The cultivated areas were mainly distributed in the downstream area of the basin in the first period, and then moved upstream, finally ending up focused on the middle reaches. This might suggest that land reclamation was directly affected by the available water resources.

\subsection{Validation of derived $\boldsymbol{R}_{\text {out }}$ with the reconstructed evolution of the terminal lakes}

The average annual volume of water that entered the terminal lakes $\left(R_{\text {out }}\right)$ in the historical periods is shown in Table 2. The estimates were obtained using Eq. (1) together with the reconstructed precipitation, streamflow and $E$ related to land 


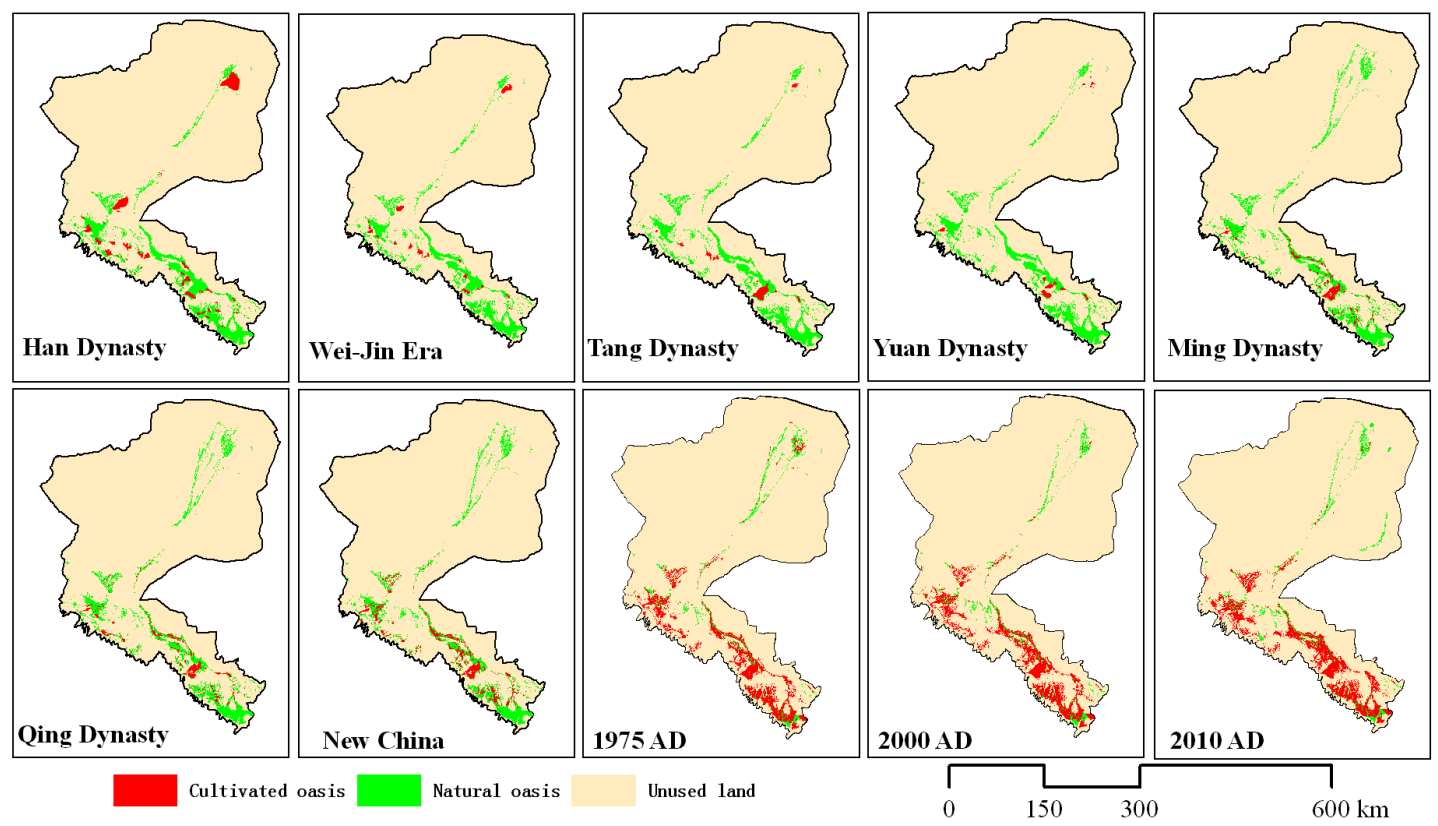

Figure 4. Land use reconstructions in historical periods and land use through image interpretation in recent periods in midstream and downstream areas of the HRB. (It should be noted that the grassland, forest and water or wetland were combined with the natural oases, and the farmland and built-up land were combined with cultivated oases in the land use in 1975, 2000 and 2010.)

use. The reconstruction of the evolution of the lake, based on lithological, geochemical and mineralogical data from the lacustrine sediment profile sequences in terminal lakes, together with some interpretation, is also described in Table 2.

There are relatively good relationships between the input volumes of water to the terminal lakes $\left(R_{\text {out }}\right)$ and the evolution of the terminal lakes in historical periods. The input of water to terminal lakes was not only determined by the streamflow from upstream, but was also affected by land use in the midstream and downstream areas of the basin. When the streamflow from the upstream area was high and the cultivation activity in the middle stream was not intense, the input of water to terminal lakes was high, such as during the Tang and Ming dynasties, and vice versa. This was reflected by the pigmentation and organic carbon content of the sediments of the terminal lakes (Qu et al., 2000; Zhang et al., 1998). After the turn of the twenty-first century, $R_{\text {out }}$ became negative, which meant that there was a deficit in groundwater recharge because of over-extraction of water for irrigation to meet the need for food (Wei, 2013).

\subsection{Reconstructed catchment water balance in the past 2000 years}

We reconstructed the catchment water cycles in the HRB for the past 2000 years from the precipitation reconstruction $(P)$ in midstream and downstream areas, the streamflow reconstruction $\left(R_{\text {in }}\right)$, land use reconstruction, evapotranspiration reconstruction $(E)$ and the derived streamflow reconstruction into terminal lakes $\left(R_{\text {out }}\right)$. Comparison of the reconstructed lake condition using the sediment record and $R_{\text {out }}$ (Table 2) shows that the reconstructed water cycles reasonably reflect variations in the water balance partitioning in the HRB over the past 2000 years.

Figure 5 shows the evolution of the catchment water balance in the HRB in the past 2000 years. Human water consumption changed clearly, especially after the founding of modern China in 1949, when streamflows from upstream areas were approximately unchanged. The main cause of the water balance changes was rapid expansion of the cultivated areas around oases, reflecting the increasing population, which was the primary driver. The cultivated oasis areas shrank from the Han Dynasty to the Yuan Dynasty and have expanded until now, the natural oasis areas continually shrank until 2000, and the areas of desertified land have increased as cultivated land was abandoned due to war, disasters or other causes. The volume of water flowing into terminal lakes remained about 1 billion $\mathrm{m}^{3}$ per year, even more in historical periods, but it decreased sharply after 1975, and even became negative. The negative values (which would be 0 in reality) probably indicate that the groundwater was being overexploited, so that there was a negative mass balance, which is consistent with falling water tables in recent times. After a water reallocation scheme was implemented in 2000 , the ecological and environment deterioration was halted and the lakes were restored. At the same time, the cultivated oasis areas, population and human water consumption increased. This was at the expense of groundwater in midstream areas combined with the benefits of a wet period of about 10 years. 
Table 2. The input volumes of water to the terminal lakes $\left(R_{\text {out }}\right)$ and evolution of the terminal lakes in historical periods.

\begin{tabular}{|c|c|c|}
\hline Periods & $\begin{array}{r}R_{\text {out }} / 10^{8} \\
\mathrm{~m}^{3} \text { year }^{-1}\end{array}$ & Evolution of terminal lakes \\
\hline Han Dynasty & 7.5 & $\begin{array}{l}\text { The lake was shrinking (Qu et al., 2000), and fine magnetic minerals peaked in the sedi- } \\
\text { ment profile (Qu et al., 2000; Zhang et al., 1998). This might be affected by low } R_{\text {out }} \text { and } \\
\text { intense reclamation in the downstream areas around the terminal lake. }\end{array}$ \\
\hline Wei-Jin era & 9.2 & $\begin{array}{l}\text { The lake was still shrinking (Qu et al., 2000), and the primary productivity of the lake was } \\
\text { low, such as Oscillatoria flavin and chlorophyll derivative (Qu et al., 2000; Zhang et al., } \\
\text { 1998). This may be because of low } R_{\text {out }} \text { and weakening reclamation due to war and other } \\
\text { factors. }\end{array}$ \\
\hline Tang Dynasty & 18.1 & $\begin{array}{l}\text { There were stable water dynamics, a large lake area and deep water reflected by the sedi- } \\
\text { ments with higher contents of silt and clay, and relatively low coarse grain content (Jin et } \\
\text { al., 2005, 2004). This was consistent with a large } R_{\text {out }} \text { during this period. }\end{array}$ \\
\hline Yuan Dynasty & 14.9 & Same as the Tang Dynasty. \\
\hline Ming Dynasty & 18.9 & $\begin{array}{l}\text { The salinity of lake water decreased and the lake expanded further (Zhang et al., 1998). } \\
\text { This was consistent with a large } R_{\text {out }}\end{array}$ \\
\hline Qing Dynasty & 11.8 & Same as the Ming Dynasty. \\
\hline Modern China in 1949 & 15.4 & $\begin{array}{l}\text { The lakes maintained a relatively large area (Zhang et al., 1998; Xiao et al., 2004). This } \\
\text { was consistent with a large } R_{\text {out. }}\end{array}$ \\
\hline 1975 & 2.0 & $\begin{array}{l}\text { Terminal lake Gaxun Nur dried up and Sogo Nur became ephemeral (Xiao et al., 2004). } \\
\text { This was because of intense exploitation of water for agriculture in the midstream area, } \\
\text { which led to streamflow decrease, and was unstable. }\end{array}$ \\
\hline 2000 & -2.8 & $\begin{array}{l}\text { The lakes dried out, and the groundwater levels decreased (Xiao et al., 2004). This was be- } \\
\text { cause of intense usage of water for agriculture in the midstream area and overexploitation } \\
\text { of the groundwater in the basin. }\end{array}$ \\
\hline 2010 & -0.5 & ake restoration started. \\
\hline
\end{tabular}

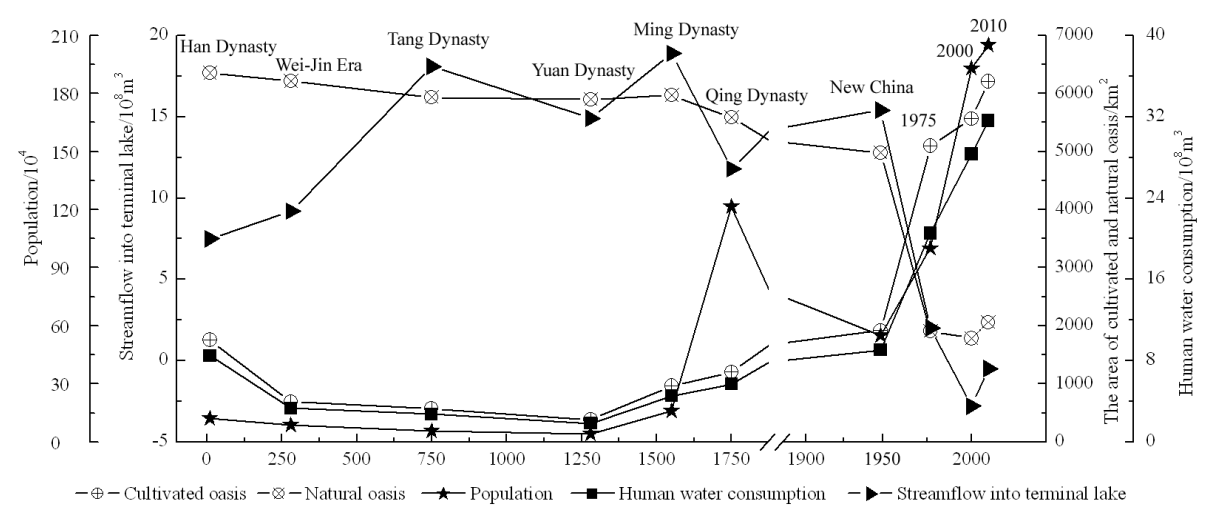

Figure 5. Changes in elements of the reconstructed catchment water balance over the past 2000 years in the midstream and downstream areas.

\subsection{Determination of the development stages of evolutionary processes of human-water relationships}

Human water consumption and natural oasis areas changed at different rates ( $k$ ) in different periods (Fig. 5). Based on their rates of change with time, we divided the evolutionary pro- cesses of the human-water relationships in the HRB over the past 2000 years into four phases (Fig. 6): (1) predevelopment (206 BC-AD 1368), (2) take-off (AD 1368-1949), (3) acceleration (AD 1949-2000), and (4) the start of rebalancing between the human and water relationships (after AD 2000). 


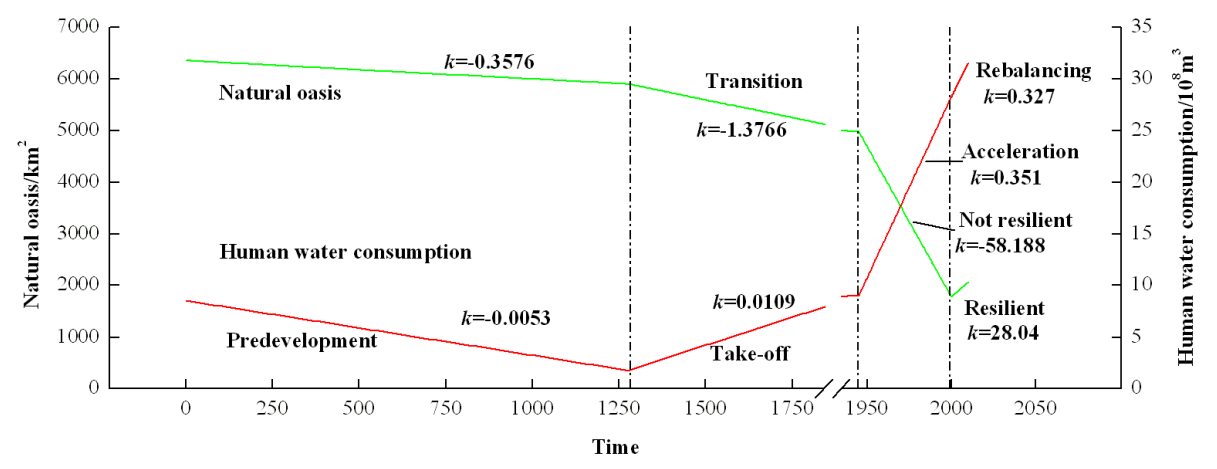

Figure 6. The development stages of evolutionary processes of human-water relationships.

The predevelopment phase started after the Han Dynasty. In the Han Dynasty, an unprecedented expansion of manmade cultivated areas based on oases occurred that were associated with defence needs, immigration and settling of farms, which changed the production mode from nomadic herding into settled farming (Cheng et al., 2011). It also corresponded to the warm and humid climate in the early western Han Dynasty (Ren et al., 2010; Xie et al., 2009). However, in the late eastern Han Dynasty, agricultural production levels declined due to population loss and damage to water conservation facilities after long-term warfare. From the southern and northern dynasties (420-581) to the Yuan Dynasty (1271-1368), the people led nomadic lifestyles, and the Hexi corridor was in a state of frequent war and dynastic change. The HRB land use was primarily pastoral, as most agricultural oases were abandoned (Li, 1998; Xie et al., 2013). In this predevelopment stage of about 1500 years, the population was stable, and cultivated area was small and focused on downstream areas. As a result, humans had few impacts on the water system, and the area of natural oasis area did not change significantly.

After the Ming Dynasty, when agricultural civilization revived, the evolution of the human-water relationships in the HRB entered the take-off stage. During this phase, oasis reclamation activities were promoted and moved upstream to the midstream area (Wu, 2000). In the middle of the Qing Dynasty, the Hexi Corridor was politically stable and free of wars, and the basic requirements for agricultural development were provided by the government, including seeds, cattle, and steel farming implements. This led to expansion of the cultivated land and agricultural development. Therefore, the population increased quickly (Shi, 2010). At the same time, irrigation technology hardly changed, and with the area of cultivated land expanding, water resource utilization became increasingly intense (Wang, 2003). It was also during this period that disputes about water arose (Cheng et al., 2011; Shen and He, 2004). This phase was relatively short, lasting about 580 years. During this phase, human water consumption increased at a rate of 1.09 million $\mathrm{m}^{3}$ per year on average, and the area of natural oases decreased at an average rate of $1.38 \mathrm{~km}^{2}$ per year. Human intervention in the water system was gradually increasing.

After modern China was founded in 1949, societal development in the HRB moved into the acceleration stage. During this stage, the population, the area of cultivated land and human water consumption increased sharply, especially after the green revolution of the 1960s and China's reform and opening-up in 1978. In addition, food self-sufficiency dominated Chinese agricultural and water resource development policy. Many wells, reservoirs and channels were built during this stage. This stage was the shortest, only 50 years long, but the human water consumption increased at an alarming rate of 35.1 million $\mathrm{m}^{3}$ per year, and the area of natural oasis area decreased at an average rate of $58 \mathrm{~km}^{2}$ per year. The influence of human activities on water resources reached its peak and the environment was seriously degraded as natural wetlands, rivers, and lakes dwindled rapidly (Xiao et al., 2004).

In order to prevent continuing environmental degradation, a series of actions and measures were implemented, such as the Natural Forest Protection Project after 2001, and another large project that turned cultivated land into forests or grasslands from 2002 to 2004. In addition, Zhangye, in the midstream area, was selected as the first experimental construction site by the Water Saving and Conservation Society (WSCS) of China in 2002. This was supported by a water reallocation scheme in 2000 in which the midstream area should discharge 950 million $\mathrm{m}^{3}$ (as measured at the ZYX station) to downstream areas in normal years (when the upstream YLX discharges 1580 million $\mathrm{m}^{3}$ of water). The Central Government's No. 1 Water Document in 2011, which limits total water diversion, promotes water use efficiency and reduces water pollution, and reinforces the changes in the relationship between humans and water that have emerged since the early 2000s. All of these actions have resulted in some improvements to downstream ecosystems, including halting the ecological and environment deterioration and restoring the lakes. The area of natural oases increased at an average rate of $28 \mathrm{~km}^{2}$ per year from 2000 to 2010 . A new state between the humans and water emerged after 2000. 


\section{Discussions and conclusions}

This paper represents an attempt to reveal the evolutionary processes of the human-water relationships in the HRB over the past 2000 years. We quantitatively analyzed the dynamics of coupled human and hydrological systems as well as the associated climatic and ecological changes in the past 2000 years within the HRB by reconstructing the catchment water balance. Based on transition theory, we divided the evolution of the human-water relationship into four stages, which are predevelopment (206 BC-AD 1368), takeoff (AD 1368-1949), acceleration (AD 1949-2000), and rebalancing (after AD 2000).

This study provides new understandings of how societal drivers and societal responses over time interact and feed back with catchment water cycles over a timescale of 2000 years. The pace of the evolutionary process varied. The predevelopment stage lasted for 1500 years, and the take-off period was shorter, at only 580 years. After that, in a period of only 50 years, the acceleration period occurred when the population increased from 0.5 to 1.9 million and the area of cultivated oases expanded by $3649 \mathrm{~km}^{2}$, which was about double that at the beginning of the acceleration stage. $\mathrm{Hu}$ man water consumption increased by 1.9 billion $\mathrm{m}^{3}$ per year, resulting in a doubling of water use over the stage. This resulted in volumes of water from midstream areas flowing into terminal lakes, decreasing from more than 1 billion $\mathrm{m}^{3}$ per year to 0 . This became the trigger for a sustainability transition in the HRB in 2000 when a water reallocation scheme was implemented. This meant that the evolutionary processes of human-water relationships in the basin entered a new stage: rebalancing. This understanding of the dynamics of transitions will assist policy makers in identifying management practices that require improvement by understanding how today's conditions and problems were created in the past. It could also help integrate management of land and water use to allow for more sustainable catchment management to combat desertification in this region.

An important part of the paper was reconstructing the catchment water balance. This relied on a range of data sources, including paleo-climates and paleo-environments reflected by dendrochronology, ice cores, lake sediments and historical drought and flood sequences, a historical atlas of China, remote sensing images and instrumented streamflow and climate data. The resulting reconstructed water balance was consistent with the dynamics of the terminal lakes in the HRB over the past 2000 years. The reconstruction provided a basis for generating baseline data against which to evaluate recent changes, for investigating the impact of human societies on hydrological systems in historical contexts, and for generating data sets for improving models of hydrological systems over timescales that exceed the length of the instrumented record (Savenije et al., 2013).

There are some important limitations on the methods and with the data collection and analysis. Several assumptions and uncertainties in the 2000 year hydrological reconstruction exist due to lack of data. Values for $E_{0}$ in the historical periods were assumed to be the same as in recent periods, which is reasonable given that the variation in average temperature was less than $2^{\circ}$. Values for $w$ may vary among different land use types and could change with time depending on the type and intensity of crops in historical periods; however, due to the lack of data, the value of $w$ for the HRB was set at 3.5. For the same reason, irrigation was set at $500 \mathrm{~mm}$ per year for the whole historical period. There was also some inconsistency between the data extracted from the different proxy materials; for example, the streamflow reconstructions by Yang et al. (2012), Qin et al. (2010), and Kang et al. (2002) using tree rings were not completely consistent. There were limitations due to the available data's representativeness of locations; for example, the data from tree rings only focused on the upstream area of the mainstream areas of the Heihe River, and the samples of lake sediment mainly focused on the terminal lake Sogo Nur. Problems of representativeness of data in various time periods and varying resolutions of data also occurred. For example, the land use maps only covered several periods, the tree ring dating can be specific to the annual scale, and the information from ice cores and lake sediment profiles was on the century scale.

The transitions seen from the four stages of evolutionary processes of human-water relationships in the HRB did not follow the standard theoretical processes. Stabilization, a typological phase in the standard transition process, did not appear. In addition, there were large differences in the rates and scales of changes and the period of time over which they occurred. Some further theoretical research is needed to explain the transition pattern, but this result shows that transitions have no fixed pattern. This paper provides a path toward an analytical approach to water-related societal transitions that should be, on the one hand, strongly attached to social science theory, and, on the other hand, firmly based on formal hydrological modeling.

Acknowledgements. This work was funded by the International Science \& Technology Cooperation Program of China (project no. 2013DFG70990), the Natural Science Foundation of China (project nos. 91125007, 91125025, 91225302, and 91225301), the Australian Research Council (project nos. DP120102917 and FT130100274), the Commonwealth of Australia under the Australia-China Science and Research Fund (project no. ACSRF800), the National Science and Technology Support projects (project no. 2011BAC07B05), and the technology innovation team of the China Academy of Science (Cross and Cooperation). We thank two anonymous reviewers for their comments on an earlier version of this paper.

Edited by: H. Li 


\section{References}

Budyko, M. I.: Climate and Life, Academic, San Diego, CA, 508 pp., 1974.

Carpenter, S. R., Cole, J. J., Pace, M. L., Batt, R., Brock, W. A., Cline, T., Coloso, J., Hodgson, J. R., Kitchell, J. F., Seekell, D. A., Smith, L., and Weidel, B.: Early warnings of regime shifts: a whole-ecosystem experiment, Science, 332, 1079-1083, 2011.

Chen, L.: Land desertification and its control strategies in the low reaches of the Heihe River, J. Nat. Resour., 1, 35-43, 1996.

Cheng, H., Huang, Y., and Zhao, L.: The human activity in Hexi Corridor during historical time, available at: http://www.paper. edu.cn (last access: 5 April 2014), 2011.

Elshafei, Y., Sivapalan, M., Tonts, M., and Hipsey, M. R.: A prototype framework for models of socio-hydrology: identification of key feedback loops and parameterisation approach, Hydrol. Earth Syst. Sci., 18, 2141-2166, doi:10.5194/hess-18-21412014, 2014.

Falkenmark, M. and Lannerstad, M.: Consumptive water use to feed humanity - curing a blind spot, Hydrol. Earth Syst. Sci., 9, 1528, doi:10.5194/hess-9-15-2005, 2005.

$\mathrm{Fu}, \mathrm{B} .:$ On the calculation of the evaporation from land surface, Sci. Atmos. Sin., 5, 23-31, 1981.

Geels, F. W.: Technological transitions as evolutionary reconfiguration processes: a multi-level perspective and a case-study, Res. Policy, 31, 1257-1274, 2002.

Holmes, J. A., Cook, E. R., and Yang, B.: Climate change over the past 2000 years in Western China, Quatern. Int., 194, 91-107, 2009.

Jin, H., Xiao, H., Sun, L., Zhang, H., Sun, Z., and Li, X.: Vicissitude of Sogo Nur and environmental-climatic change during last 1500 years, Sci. China Ser. D, 47, 61-70, 2004.

Jin, H., Xiao, H., Zhang, H., and Sun, Z.: Evolution and climate changes of the Juyan Lake revealed from grain size and geochemistry element since 1500aBP, J. Glaciol. Geocryol., 27, 233-240, 2005.

Kallis, G.: Coevolution in water resource development the vicious cycle of water supply and demand in Athens, Greece, Ecol. Econ., 69, 796-809, 2011.

Kang, X., Cheng, G., Kang, E., and Zhang, Q.: Mountainous runo_reconstruction of Heihe River during past 1000 years using tree-ring, Sci. China Ser. D, 32, 49-53, 2002.

Li, B.: An investigation and study on the desertification of the ancient oases from Han to Tang dynasties in the Hexi corridor, Acta Geogr. Sin., 53, 106-115, 1998.

Liu, K., Yao, Z., and Thompson, L. G.: A pollen record of Holocene climatic changes from the Dunde ice cap, QinghaiTibetan Plateau, Geology, 26, 135-138, 1998.

Liu, Y., Tian, F., Hu, H., and Sivapalan, M.: Socio-hydrologic perspectives of the co-evolution of humans and water in the Tarim River basin, Western China: the Taiji-Tire model, Hydrol. Earth Syst. Sci., 18, 1289-1303, doi:10.5194/hess-18-12892014, 2014.

Lowry, D. P. and Morrill, C.: Changes in the Global Hydrological Cycle: Lessons from Modeling Lake Levels at the Last Glacial Maximum, American Geophysical Union, Fall Meeting, San Francisco, California, USA, 5-9 December 2011, 2011.

Montanari, A., Young, G., Savenije, H., Hughes, D., Wagener, T., Ren, L., Koutsoyiannis, D., Cudennec, C., Toth, E., and Grimaldi, S.: "Panta Rhei - Everything Flows": change in hy- drology and society - the IAHS Scientific Decade 2013-2022, Hydrolog. Sci. J., 58, 1256-1275, 2013.

Pataki, E., Carreiro, M., Cherrier, J., Grulke, E., Jennings, V., Pincetl, S., Pouyat, V., Whitlow, H., and Zipperer, C.: Coupling biogeochemical cycles in urban environments: ecosystem services, green solutions, and misconceptions, Front. Ecol. Environ., 1, 27-36, doi:10.1890/090220, 2011.

Qin, C., Yang, B., Burchardt, I., Hu, X., and Kang, X.: Intensified pluvial conditions during the twentieth century in the inland Heihe River Basin in arid northwestern China over the past millennium, Global Planet. Change, 72, 192-200, 2010.

Qu, W., Wu, R., Wang, S., and Zhang, Z.: Sedimentary pigment and its environmental signification of East Juanyanhai in Inner Mongolia since the past 2600 years, Acta Sendiment. Sin., 48, 13-17, 2000.

Ren, Z., Lu, Y., and Yang, D.: Drought and flood disasters and rebuilding of precipitation sequence in Heihe River basin in the past 2000 years, J. Arid Land Resour. Environ., 24, 91-95, 2010.

Röckstrom, J., Karlberg, L., Wani, S. P., Barron, J., Hatibu, N., Oweis, T., Bruggeman, A., Farahanie, J., and Zhu, Q.: Managing water in rainfed agriculture - the need for a paradigm shift, Agr. Water Manage., 97, 543-550, 2010.

Rotmans, J.: Societal Innovation: Between Dream and Reality Lies Complexity, DRIFT Research Working Paper, Erasmus Research Institute of Management (ERIM), Rotterdam, the Netherlands, doi:10.2139/ssrn.878564, 2005.

Saito, K., Hirai, M., and Yonekura-Sakakibara, K.: Decoding genes with coexpression networks and metabolomics -"majority report by precogs", Trends Plant Sci., 13, 36-43, 2008.

Savenije, H. H. G., Hoekstra, A. Y., and van der Zaag, P.: Evolving water science in the Anthropocene, Hydrol. Earth Syst. Sci., 18, 319-332, doi:10.5194/hess-18-319-2014, 2014.

Shao, X., Xu, Y., Yin, Z.-Y., Liang, E., Zhu, H., and Wang, S.: Climatic implications of a 3585-year tree-ring width chronology from the northeastern Qinghai-Tibetan Plateau, Quaternary Sci. Rev., 29, 2111-2122, 2010.

Shen, J., Zhang, E., and Xia, W.: Records from lake sediments of the Qinghai Lake to mirror climatic environmental changes of the past about 1000 years, Quatern. Sci., 21, 508-513, 2001.

Shen, M. and He, L.: Comparison of new and old equal water regime in Heihe River basin, Yellow River, 26, 27-29, 2004.

Sheppard, P., Tarasov, P., Graumlich, L., Heussner, K.-U., Wagner, M., Österle, H., and Thompson, L.: Annual precipitation since 515 BC reconstructed from living and fossil juniper growth of northeastern Qinghai Province, China, Clim. Dynam., 23, 869881,2004

Shi, J.: Integrating humanistic and scientific studies to reveal the changes of Khara Khoto, Studies in humanity and environment of Khara Khoto, in: Proceedings of international symposium on the humanity and environment of Khara Khoto region, Renmin University of China Press, Beijing, 1-4, 2007.

Shi, L.: Study on the spatio-temporal process of oasisization and desertification in the period of the Ming, Qing dynasty and Republic of China in the middle reaches, MD thesis, Lanzhou University, Lanzhou, 2010.

Shi, M., Wang, L., and Wang, X.: A study on changes and driving factors of agricultural water supply and demand in Zhangye after water reallocation of the Heihe River, Resour. Sci., 33, 1489 1497, 2011. 
Sivapalan, M., Blöschl, G., Zhang, L., and Vertessy, R.: Downward approach to hydrological prediction, Hydrol. Process., 17, 21012111, 2003.

Sivapalan, M., Savenije, H. H., and Blöschl, G.: Socio-hydrology: a new science of people and water, Hydrol. Process., 26, 12701276, 2012.

Tàbara, J. D. and Ilhan, A.: Culture as trigger for sustainability transition in the water domain: the case of the Spanish water policy and the Ebro river basin, Reg. Environ. Change, 8, 59-71, 2008.

Tan, Q.: The Historical Atlas of China, China Cartographic Publishing House, Beijing, 1996.

Thompson, S. E., Sivapalan, M., Harman, C. J., Srinivasan, V., Hipsey, M. R., Reed, P., Montanari, A., and Blöschl, G.: Developing predictive insight into changing water systems: useinspired hydrologic science for the Anthropocene, Hydrol. Earth Syst. Sci., 17, 5013-5039, doi:10.5194/hess-17-5013-2013, 2013.

Vörösmarty, C. J., McIntyre, P. B., Gessner, M. O., Dudgeon, D., Prusevich, A., Green, P., Glidden, S., Bunn, S. E., Sullivan, C. A., Reidy Liermann, C., and Davies, P. M.: Global threats to human water security and river biodiversity, Nature, 467, 555-563, 2010.

Wang, G., Yang, L., Chen, L., and Jumpei, K.: Impacts of land use changes on groundwater resources in the Heihe River basin, Acta Geogr. Sin., 60, 456-466, 2005.

Wang, G., Xie, Y., Wang, X., Yu, L., and Shi, Z.: Data reconstruction of Heihe River basin cultivated land area prior to the Ming dynasty, Resour. Sci., 35, 362-369, 2013.

Wang, Y.: The development history of water conservancy facilities in Heihe River basin, Gansu Nationalities Press, Lanzhou, 2003.

Wei, H.: Groundwater age and sustainability based on process simulation in Zhangye basin, $\mathrm{PhD}$ thesis, Cold and Arid Regions Environment and Engineering Research Institute, Chinese Academy of Sciences, Lanzhou, 2013.

Wimmer, A.: Models, methodologies, and metaphors on the move, in: Understanding Change Models, Methodologies, and Metaphors, edited by: Wimmer, A. and Kössler, R., Palgrave MacMillan, London, England, 2006.

Woodhouse, A., Gray, T., and Meko, M.: Updated streamflow reconstructions for the Upper Colorado River Basin, Water Resour. Res., 40, W05415, doi:10.1029/2005WR004455, 2006.

$\mathrm{Wu}, \mathrm{X}$.: Historical variance of the ecological environment in the inland river area along the Hexi corridor, J. Lanzhou Univ. (Social Sciences), 28, 46-49, 2000.

Xiao, S. and Xiao, H.: Farming-grazing vicissitude and man-land relation evolution of Ejin Banner in historical period, J. Desert Res., 24, 449-451, 2004.

Xiao, S. and Xiao, H.: Advances in the study of the water regime process and driving mechanism in the Heihe River basin, Adv. Earth Sci., 23, 748-755, 2008.

Xiao, S., Xiao, H., Zhou, M., Si, J., and Zhang, X.: Water level change of the west Juyan Lake in the past 100 years recorded in the tree ring of the shrubs in the lake banks, J. Glaciol. Geocryol., 26, 557-562, 2004.
Xie, Y.: Dataset of cultivated oasis distribution in the Heihe River Basin during the historical period, Heihe Plan Science Data Center, Lanzhou, China, doi:10.3972/heihe.092.2013.db, 2013.

Xie, Y., Chen, F., and Qi, J.: Past desertification processes of Minqin Oasis in arid China, Int. J. Sust. Dev. World, 16, 260-269, 2009.

Xie, Y., Wang, X., Wang, G., and Yu, L.: Cultivated land distribution simulation based on grid in middle reaches of Heihe River basin in the historical periods, Adv. Earth Sci., 28, 71-78, 2013.

Yang, B., Qin, C., Shi, F., and Sonechkin, D. M.: Tree ring-based annual streamflow reconstruction for the Heihe River in arid northwestern China from AD 575 and its implications for water resource management, Holocene, 22, 773-784, 2012.

Yang, B., Qin, C., Wang, J., He, M., Melvin, T. M., Osborn, T. J., and Briffa, K. R.: A 3,500-year tree-ring record of annual precipitation on the northeastern Tibetan Plateau, P. Natl. Acad. Sci. USA, 111, 2903-2908, 2014.

Yang, D., Sun, F., Liu, Z., Cong, Z., Ni, G., and Lei, Z.: Analyzing spatial and temporal variability of annual water-energy balance in nonhumid regions of China using the Budyko hypothesis, Water Resour. Res., 43, W04426, doi:10.1029/2006WR005224, 2007.

Zhang, L., Dawes, W., and Walker, G.: Response of mean annual evapotranspiration to vegetation changes at catchment scale, Water Resour. Res., 37, 701-708, 2001.

Zhang, L., Hickel, K., Dawes, W., Chiew, F. H., Western, A., and Briggs, P.: A rational function approach for estimating mean annual evapotranspiration, Water Resour. Res., 40, W02502, doi:10.1029/2003WR002710, 2004.

Zhang, L., Pang, B., Xu, Z., and He, R.: Impacts of climate change and LULC on hydrological processes in the Gulang River basin, Sounth-to-North Water Transfers and Water Science \& Technology, 12, 42-46, 2014.

Zhang, Z., Wu, R., Wang, S., Xia, W., Wu, Y., and Qu, W.: Environmental changes recorded by lake sediments from East Juyanhai Lake in Inner Mongolia during the last 2600 years, J. Lake Sci., 10, 44-51, 1998.

Zhao, L. and Ji, X.: Quantification of transpiration and evaporation over agricultural field using the FAO-56 Dual Crop Coe_cient Approach - A case study of the maize field in an oasis in the middlestream of the Heihe River Basin in northwest China, Scient. Agr. Sin., 43, 4016-4026, 2010.

Zheng, J. and Wang, S.: Assessment on climate change in China for the last 2000 years, Acta Geogr. Sin., 60, 21-31, 2005.

Zheng, J., Shao, X., Hao, Z., and Ge, Q.: An overview of research on climate change in China during the past 2000 years, Geogr. Res., 29, 1561-1570, 2010.

Zhou, L. and Yang, G.: Ecological economic problems and development patterns of the Arid Inland River Basin in Northwest China, Ambio, 35, 316-318, 2006. 